\begin{tabular}{|c|c|c|}
\hline \multirow{3}{*}{$\begin{array}{r}\text { Case Reports in } \\
\text { Gastroenterology }\end{array}$} & \multirow{2}{*}{\multicolumn{2}{|c|}{ Case Rep Gastroenterol 2016;10:568-573 }} \\
\hline & & \\
\hline & $\begin{array}{l}\text { DOI: } 10.1159 / 000450699 \\
\text { Publisnea onine: Uctover 18, } 2016\end{array}$ & $\begin{array}{l}\text { (c) } 2016 \text { The Author(s) } \\
\text { Published by S. Karger AG, Base } \\
\text { www.karger.com/crg }\end{array}$ \\
\hline & \multicolumn{2}{|c|}{$\begin{array}{l}\text { This article is licensed under the Creative Commons Attribution-NonCommercial } 4.0 \\
\text { International License (CC BY-NC) (http://www.karger.com/Services/OpenAccessLicense). } \\
\text { Usage and distribution for commercial purposes requires written permission. }\end{array}$} \\
\hline
\end{tabular}

\title{
Elevated Lipase during Initial Presentation of Ulcerative Colitis in a Pediatric Patient: Do We Check for It?
}

\author{
Piyali Ray Melissa R. Van Arsdall \\ University of Texas Health Science Center, Houston, Tex., USA
}

\section{Keywords}

Lipase $\cdot$ Pancreatitis $\cdot$ Inflammatory bowel disease $\cdot$ Pediatric patient

\begin{abstract}
There are very few reports of elevated lipase in pediatric inflammatory bowel disease (IBD). Symptoms of pancreatitis may be masked by abdominal pain in pediatric IBD. During the initial presentation of IBD in our patient, lipase was elevated to more than 3 times the upper limit of normal. Normalization of values coincided with remission of IBD. This may be due to extraintestinal involvement of the pancreas as part of the inflammatory process or due to leakage of pancreatic enzymes from an inflamed gut or mediated by inflammatory cytokines. Checking pancreatic enzymes during initial presentation of IBD may, therefore, be important to determine if pancreatic involvement has resulted from the inflammation in IBD or as an adverse effect of therapy. If unchecked, recurrent subclinical pancreatitis may be masked by IBD symptoms and missed prior to starting IBD therapy. This may result in chronic pancreatic insufficiency as reported in 50\% of adults with IBD. Early detection of elevated pancreatic enzymes in IBD may help direct the management strategy, as treatment of the underlying inflammation in IBD may be the most important management for resolution of pancreatitis instead of cessation of therapy for fear of iatrogenic medication-induced pancreatitis.
\end{abstract}




\section{Case Reports in Gastroenterology}

Case Rep Gastroenterol 2016;10:568-573 DOI: 10.1159/000450699

C 2016 The Author(s). Published by S. Karger AG, Basel www.karger.com/crg

Ray and Van Arsdall: Elevated Lipase during Initial Presentation of Ulcerative Colitis in a Pediatric Patient: Do We Check for It?

\section{Background}

Inflammatory bowel disease (IBD) comprises a myriad of different presentations, levels of severity and responses to treatment. It is especially known that pediatric IBD represents more extensive inflammation with a predilection for colitis [1]. It is an immune-mediated inflammation of the gastrointestinal tract arising out of a host immune dysregulation with genetic and environmental influences. The immune pathophysiology often results in extraintestinal manifestations in IBD that involves multiple organs including the bones and joints, skin, liver and pancreas. The incidence of extraintestinal manifestations has been reported to range from 18 to $47 \%$ of pediatric and adult patients with IBD. This includes both acute and chronic pancreatitis as well as pancreatic insufficiency, the latter seen especially in adult IBD.

Pancreatitis and hyperlipasemia in the absence of pancreatitis are uncommon features of pediatric IBD. There have been very limited and no recent published data on the incidence of elevated lipase in pediatric IBD [1,2]. Stawarski and Iwańczak [2] conducted a 4-year study in over 100 children with ulcerative colitis or Crohn's disease (CD) and found the incidence of acute pancreatitis to be $4.5 \%$ in children with CD and $5.1 \%$ in children with ulcerative colitis. Acute pancreatitis in children has been increasing in incidence over the past couple of decades and some authors have attributed this to a rise in systemic illness in children.

The association of pancreatitis with IBD may be due to the systemic inflammation but may also arise from other causes such as a direct autoimmune hit to the pancreas, the effect of macromolecules of lipase and most importantly, the effect of medications. Drug-induced pancreatitis is also on the rise. The most common agents used in the treatment of IBD are associated with drug-induced pancreatitis. These include sulfasalazine, 5-aminosalicylic acid, azathioprine, metronidazole and steroids. This effect of drug-induced pancreatitis makes it challenging to manage pancreatitis in children with IBD, since removal of the offending drug will interfere with maintenance of remission and control of the underlying inflammation in IBD.

\section{Case Report}

A 13-year-old Hispanic female presented to the pediatric gastroenterology clinic with complaints of hematochezia described as soft to loose stools with a passage of blood clots for the preceding 4-6 months. She reported occasional mild abdominal pain, but denied fever, nausea, vomiting, loss of appetite, weight loss or nocturnal symptoms and had minimal urgency and tenesmus.

Her laboratory workup was significant for elevated fecal calprotectin of $225 \mu \mathrm{g} / \mathrm{g}$ (reference $\leq 162.9 \mu \mathrm{g} / \mathrm{g}$ ) and an elevation in pancreatic enzymes with amylase of $102 \mathrm{u} / \mathrm{l}$ (reference 25-115 u/l) and lipase of 1,053 u/l (reference 73-393 u/l). An ultrasound revealed no pancreatic abnormality and normal biliary system. Liver enzymes, ESR, and CRP were obtained to look for evidence of systemic inflammation but were normal.

Following negative stool studies for infection, due to persistent hematochezia, she underwent endoscopy that revealed left-sided colitis with erythematous friable mucosa (fig. 1). Pathology reported chronic active colitis with cryptitis and crypt abscesses, with most prominent changes in the left colon, Paneth cell metaplasia and significant chronic inflammation. Serologic testing with an IBD-7 panel that differentiates CD from ulcerative colitis based on antibodies was consistent with ulcerative colitis. 
She was started on balsalazide (750 mg by mouth 3 times daily), with some improvement, but ultimately required steroid suppositories (rectacort 2 times a day for 2 weeks) for complete resolution of her rectal bleeding. Her lipase continued to rise, peaking at 1,223 u/l, which was $>3$ times the upper limit of normal (lab range 73-393 u/l). Testing was also repeated at a different laboratory (with range 6-70 u/l) that showed persistent elevation to $>3$ times the upper limit of normal, at 305-374 u/l.

After 3 months of treatment of her ulcerative colitis, her lipase began to show a downward trend approaching normal values at $73 \mathrm{u} / \mathrm{l}$ (fig. 2). This correlated with clinical improvement of her ulcerative colitis, as she had normal regular bowel movements with no further bleeding or abdominal pain. Her fecal calprotectin also correlated with clinical remission and normalized to $23.9 \mu \mathrm{g} / \mathrm{g}$.

She was in remission for a whole year before reporting recurrence of hematochezia. Follow-up calprotectin increased to $474 \mu \mathrm{g} / \mathrm{g}$. Her flare was found to be a result of noncompliance with balsalazide and was quickly suppressed with another course of steroid suppositories that successfully resolved her hematochezia within a week. Her lipase remained normal at $129 \mathrm{u} / \mathrm{l}$. We switched her maintenance medication to Lialda for ease of administration ( $2.4 \mathrm{~g}$ by mouth once daily) and counseled her on the need for compliance with medications. She has since continued to be in remission.

\section{Discussion}

Acute and chronic pancreatitis as well as pancreatic insufficiency have been reported in association with IBD, although it is often difficult to diagnose pancreatitis as it may remain silent and masked by the symptoms of systemic inflammation in IBD. Most of the prior reports of pancreatitis have been in association with CD but there are also a few reports of pancreatitis with ulcerative colitis. Several potential pathophysiological processes have been suggested for hyperlipasemia with or without pancreatitis in IBD [3-5]. There might be an abnormal passage of pancreatic enzymes from the gut lumen into the blood due to increased permeability of the inflamed mucosa in IBD. More recent reports suggest that pancreatitis and the level of pancreatic enzymes may reflect the clinical course and extent of disease in IBD $[2,6,7]$. The effect of inflammatory mediators and cytokines released from the inflamed gut on the pancreas may also contribute to pancreatic damage and leak of pancreatic enzymes into the blood [6-8].

Some experts suggest that direct involvement of the pancreas as part of the spectrum of inflammation in IBD might explain a recent report of a pancreatic granuloma noted in CD [6]. Another mechanism may be inflammatory damage to the pancreatic ducts resulting in enzyme accumulation in the abnormal ductal system leading to further pancreatic inflammation [8]. Heikius et al. [6] found that at least $8 \%$ of IBD patients have pancreatic duct abnormalities, and that $50 \%$ of IBD patients with primary sclerosing cholangitis have pancreatographic changes.

Pancreatic involvement in IBD may also be a part of a common immune disorder whereby the target cells of gut epithelium and pancreas share a similar molecular structure lending themselves to antigenic mimicry $[1,8]$. There have been reports of the rarer variant, autoimmune pancreatitis, occurring more often in IBD patients [2]. Studies have reported the presence of periductal lymphocytic inflammatory infiltrates and perilobular fibrosis [8]. Martinelli et al. [1] reported correlation between pancreatic inflammation and IBD disease activity, with $91 \%$ of their patients eliciting acute pancreatitis during active disease. They 
Ray and Van Arsdall: Elevated Lipase during Initial Presentation of Ulcerative Colitis in a Pediatric Patient: Do We Check for It?

also reported that patients with recurrent pancreatitis had higher disease activity indices (PCDAI and PUCAI) for pediatric CD and ulcerative colitis, respectively. Park et al. [10] showed an association between decreasing amylase and lipase levels and improving PCDAI and reported normalization of pancreatic enzymes 3 months after the start of treatment for CD.

Another remote possibility is cryptogenic hyperlipasemia without pancreatitis where macrolipase or immunoglobulin-linked enzymes are suggested to be induced by autoimmune mechanisms resulting in reduced glomerular excretion of the large macrolipase molecules thereby increasing serum half-life of lipase [4, 9]. This may not be associated with pancreatic inflammation with no subsequent sequelae of pancreatic insufficiency.

\section{Conclusion}

Clinical symptoms of IBD-associated pancreatitis are found in approximately $2 \%$ of patients while exocrine pancreatic insufficiency has been reported in $21-80 \%$ patients and histological changes observed in $38-53 \%$ of postmortem pathological exams [8]. Subclinical or silent pancreatitis may be masked by symptoms attributed to IBD, hence underreported $[1,6]$. If undetected, it may lead to subsequent chronic pancreatitis or exocrine pancreatic insufficiency, which has been reported in $50 \%$ of IBD patients with a history of acute pancreatitis in adult studies $[6,8]$.

This case shows that checking pancreatic enzymes during initial presentation may be important to determine if pancreatic involvement has resulted from the inflammation in IBD or as an adverse effect of therapy. One should use caution in considering change or cessation of a particular treatment regimen in IBD with pancreatic involvement, as treatment of the underlying inflammation in IBD may be the most important management for resolution of pancreatitis $[3,8]$. Longitudinal observation in our patient and follow-up pediatric studies are required to see if subclinical pancreatitis or asymptomatic elevation in pancreatic enzymes results in clinically significant pancreatic disease later in life.

\section{Acknowledgments}

Each author made substantial contributions to the manuscript including analysis and interpretation of data, literature research, review and revision of the manuscript. P.R. and M.R.V.A. took care of the patient. P.R. drafted the manuscript and researched the literature. M.R.V.A. edited the manuscript. No specific funding has been received for this work.

\section{Statement of Ethics}

The authors declare that they have no ethical conflicts to disclose. All procedures were conducted in accordance with the ethical standards of practice.

\section{Disclosure Statement}

None of the authors has any conflict of interest to declare. 


\section{Case Reports in \\ Gastroenterology}

\begin{tabular}{l|l}
\hline Case Rep Gastroenterol 2016;10:568-573 \\
\hline DOI: 10.1159/000450699 & $\begin{array}{l}\text { C 2016 The Author(s). Published by S. Karger AG, Basel } \\
\text { www.karger.com/crg }\end{array}$ \\
\hline
\end{tabular}

Ray and Van Arsdall: Elevated Lipase during Initial Presentation of Ulcerative Colitis in a Pediatric Patient: Do We Check for It?

\section{References}

1 Martinelli M, Caterina S, Maria TI, et al: Natural history of pancreatic involvement in paediatric inflammatory bowel disease. Dig Liver Dis 2015;47:384-389.

-2 Stawarski A, Iwańczak F: Incidence of acute pancreatitis in children with inflammatory bowel disease. Pol Merkur Lekarski 2004;17:33-36.

-3 Rayees N, Rubina A, Antonino TD: Initial presentation of ulcerative colitis with acute pancreatitis. Am J Gastroenterol 2000;95:825-826.

4 Dick CK, Carli C, Ira N: Elevated lipase without pancreatitis in infectious colitis. J Emerg Med 2015;48:26-28.

5 Tromm A, Höltmann B, Hüppe D, et al: Hyperamylasemia, hyperlipasemia and acute pancreatitis in chronic inflammatory bowel diseases. Leber Magen Darm 1991;21:15-16, 19-22.

-6 Heikius B, Niemela S, Lehtola J, et al: Elevated pancreatic enzymes in inflammatory bowel disease are associated with extensive disease. Am J Gastroenterol 1999;94:1062-1069.

-7 Bokemeyer B: Asymptomatic elevation of serum lipase and amylase in conjunction with Crohn's disease and ulcerative colitis. Z Gastroenterol 2002;40:5-10.

8 Barthet M, Lesavre N, Desplats S, et al: Frequency and characteristics of pancreatitis in patients with inflammatory bowel disease. Pancreatology 2006;6:464-471.

-9 Yoshiaki O, Junya T, Yutaka S, et al: Macrolipasemia in Crohn's disease. Pancreas 1998;16:205-210.

10 Chan BP, Won M, Pyoung RC, et al: A case of idiopathic pancreatitis in a patient with Crohn's disease. Korean J Gastroenterol 2009;53:251-256.
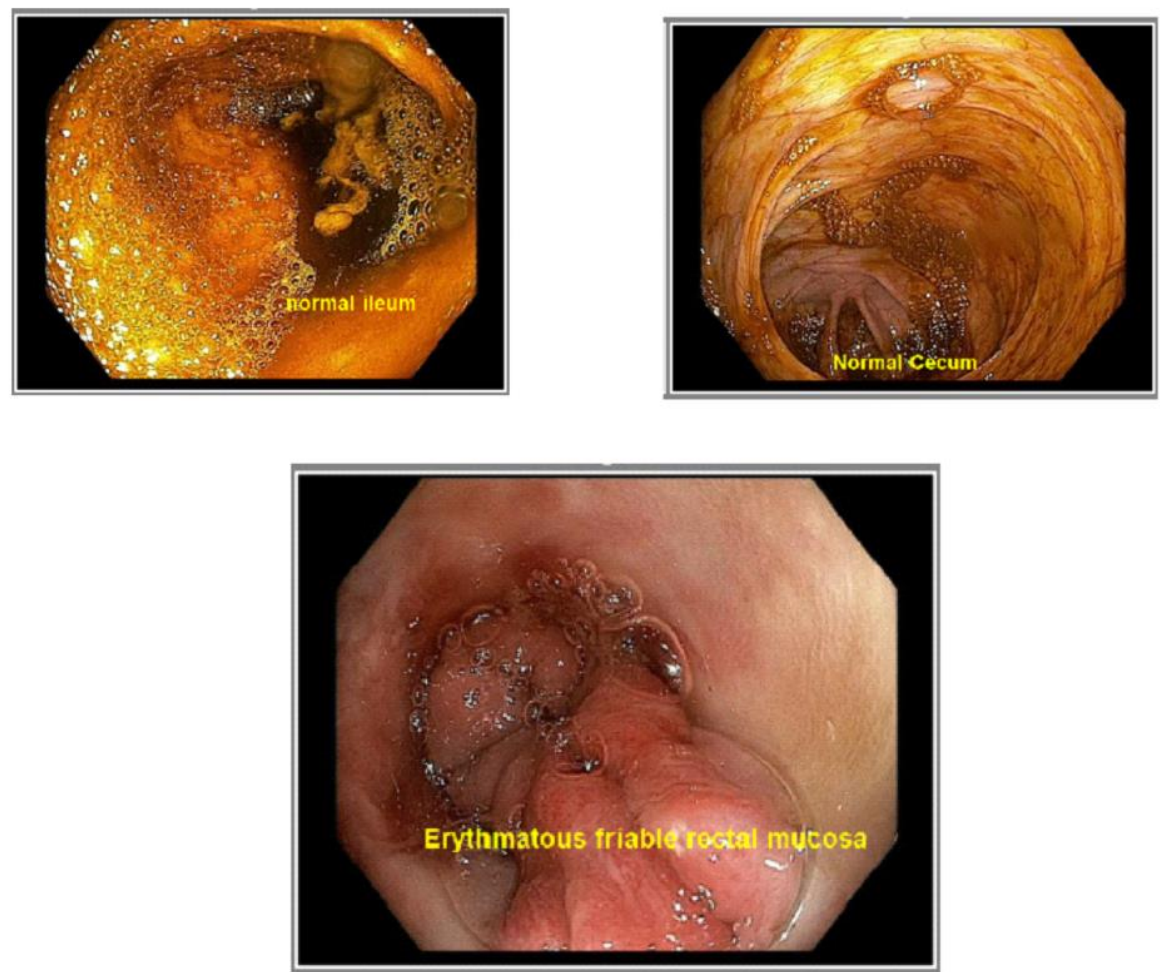

Fig. 1. Endoscopy findings of predominant left-sided colitis. 


\section{Case Reports in Gastroenterology}

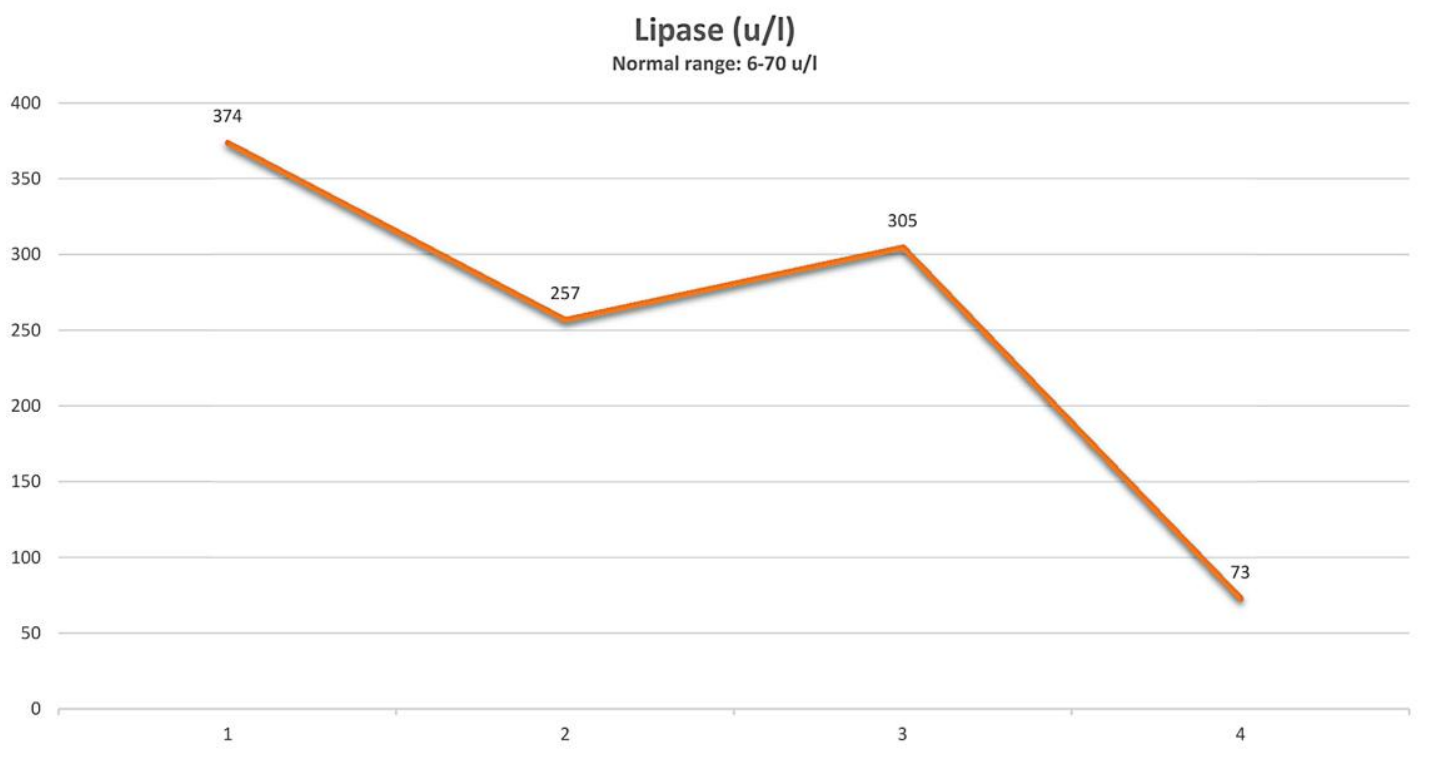

Fig. 2. Lipase trend during induction and remission of ulcerative colitis.

Ray and Van Arsdall: Elevated Lipase during Initial Presentation of Ulcerative Colitis in a Pediatric Patient: Do We Check for It?

Lipase (u/I) 